\title{
Learning Approaches Among Medical Undergraduates and Pre-Intern Doctors of A Selected University In Sri Lanka
}

Sajith Edirisinghe ( $\nabla$ edirisinghe@sjp.ac.lk)

University of Sri Jayewardenepura

\section{Dulmini De Silva}

University of Sri Jayewardenepura

Indunil Liyanage

University of Sri Jayewardenepura

Malith Niluka

University of Sri Jayewardenepura

Kasuni Madushika

University of Sri Jayewardenepura

Sandeepani Deegodagamage

University of Sri Jayewardenepura

Chanuka Wijesundara

University of Sri Jayewardenepura

Harsha Dissanayake

University of Sri Jayewardenepura

Surangi Yasawardene

University of Sri Jayewardenepura

\section{Research Article}

Keywords: learning approaches, medical undergraduates, medical curriculum

Posted Date: September 28th, 2021

DOl: https://doi.org/10.21203/rs.3.rs-923379/v1

License: (c) (i) This work is licensed under a Creative Commons Attribution 4.0 International License.

Read Full License 


\section{Abstract \\ Background}

Medical education is constantly evolving to suit the changes in the field. It is a challenge to acquire the necessary knowledge, attitudes and skills within a limited time period in order to become a proficient doctor. This study aims to determine and compare the learning approaches (deep, strategic, superficial) used by medical undergraduates and pre-intern doctors.

\section{Methods}

Learning approaches of 138 pre-clinical medical undergraduates and pre-intern doctors of the University of Sri Jayewardenepura were assessed using the Approaches and Study Skills Inventory for Students (ASSIST) questionnaire. Data were analyzed using SPSS v-16 and Brown-Forsythe test.

\section{Results}

The strategic approach was identified as the predominant learning approach among 138 participants. One hundred and eight (108) participants (78.3\%) used this method while $21(15.2 \%)$ and $9(6.5 \%)$ participants used the deep approach and the surface apathetic approach, respectively. Majority of both undergraduates $[77.6 \%(83 / 107)]$ and pre-interns $[80.6 \%(25 / 31)]$ used the strategic approach. This finding was also consistent between the 2 genders with a majority of males [69.6\% (32/46)] as well as females [82.6\% (76/92)] following the strategic approach. No significant difference in learning approaches was found to be present between undergraduate and pre-intern groups.

\section{Conclusions}

This study demonstrates that a majority of medical undergraduates and pre-intern doctors prefer the strategic learning approach. This implies that the medical curriculum has not adequately promoted the deep learning approach over the five-year period of studentship and this needs to be addressed in a subsequent curriculum change in order to promote a deep learning approach.

\section{Background}

Medicine is a field of study in which knowledge of the appropriate techniques of studying is just as critical as the content itself. The study of medicine is an extensive exercise spanning over 5 years a and therefore it is of paramount importance that the students possess a suitable approach to it and continue to be effective lifelong learners in the workplaces, making conscious decisions to direct their own development. Teaching medicine in a way that it is assimilated into memory, retained and effectively interpreted by the learner is a considerable challenge faced by educators. The shift from instructive 
teacher-centered and subject-based teaching to the use of interactive, problem-based, student-centered learning has emerged to meet this challenge and is a crucial development in the field of medical education.

Most medical faculties have structured their curricula taking into consideration current approaches in education. These curricula have been developed incorporating new methods of teaching and learning to varying degrees (1). Differences in the learning styles and learning approaches have important implications in the development of effective medical curricula in both undergraduate and postgraduate education (2). Teachers who are aware of the predominant learning approaches used by their students are better able to modify their teaching to match those approaches $(3,4)$. Likewise, students with awareness of their learning approach are capable of seeking out techniques to enhance that approach in a manner that results in accomplishing both their educational achievements and satisfaction.

Learning approach is defined as the desired way in which a student organizes the acquired knowledge for the purpose of understanding and learning (5). These approaches are namely, deep approach (DA), surface apathetic approach (SAA) and strategic approach (SA) (6). DA is characterized by an attempt to acquire in-depth knowledge about an area and at the same time relate new concepts to each other and to the existing knowledge. This approach is favored by educators as it encourages a higher form of learning which is not focused solely around achieving high grades. In contrast, SAA is restricted to memorization of the syllabus and is employed by students who may be lacking in purpose in their studies and are not motivated by either a desire to gain deep understanding of the content or good grades. SA students are versatile in that they are capable of engaging in either deep or superficial learning as appropriate and are primarily concerned with achievement $(7,8)$. They consider the assessment of their performance with great importance and therefore are more likely to learn with a desire of performing well in examinations, rather than acquiring holistic knowledge about the subject (9). Considering the features of these three approaches, it is understandable that using DA and SA for learning are associated with academic success while using SAA is likely to result in failures (10).

School education is usually teacher-centered and relies on the ability of teachers to impart knowledge to their students who take on a passive approach to their studies. In Sri Lanka, the General Certificate in Education (GCE) - Advanced Level examination is held at the end of 13 years of school education and determines entry to universities based on the performance of students. The Faculty of Medical Sciences of the University of Sri Jayewardenepura, established 28 years ago, has steadily progressed over the years and is one of the leading medical faculties in the country. It has an integrated medical curriculum comprising of 3 phases. In the first phase, pre-clinical subjects (Anatomy, Biochemistry and Physiology) are taught over five terms and the First MBBS examination is held at the end of this phase. Paraclinical subjects such as Microbiology, Parasitology, Pathology, Pharmacology, Forensic Medicine and Community Medicine are taught over the next 2 years while undergoing clinical rotations and is assessed by the Second MBBS examination. The final year is focused on clinical subjects (Medicine, Surgery, Obstetrics \& Gynaecology, Paediatrics, Psychiatry and Family Medicine) and students face the Final MBBS examination approximately 5 years after the commencement of their medical undergraduate 
course. The medical curriculum taught at the faculty is module-based and gives prominence to clinical scenario-based learning technique. Knowledge, attitudes and skills are delivered via a multitude of methods and the students are assessed throughout the programme by conducting continuous assessments, both formative and summative.

Considering the differences between school and university education, it is reasonable to expect noteworthy differences in the learning approaches used by medical students and pre-intern medical graduates; i.e., medical students would be expected to prefer strategic learning, while pre-interns would be expected to place greater emphasis on deep learning. However, there are only a few published studies that focus on learning approaches among Sri Lankan medical students. This study was aimed to determine and compare the learning approaches used by medical undergraduates and pre-intern doctors who have successfully completed their MBBS degree program. By identifying these learning approaches, medical educators could modify the curricula in order to encourage DA instead of SA and SAA.

\section{Methods}

\section{Participants}

This cross-sectional study was conducted at the Faculty of Medical Sciences, University of Sri Jayewardenepura involving 138 participants. Medical undergraduates who had passed their First MBBS examination waiting to start their third year and pre-intern medical graduates who had successfully completed their Final MBBS examination were selected for the study. Informed consent was obtained from all those who volunteered to participate. Ethical approval for the study was obtained from the Ethics Review Committee of the Faculty of Medical Sciences, University of Sri Jayewardenepura.

\section{Questionnaire}

Data collection was performed using a 2-part questionnaire comprising of one section on demographic details and the other, self-administered ASSIST questionnaire. The Approaches to Study Skills Inventory for Students (ASSIST) is a questionnaire developed by the Enhancing Teaching-Learning Environments project in the United Kingdom which helps determine the learning approaches used by an individual and identify which of the three is predominant (6). One out of the four sections of the questionnaire "Approaches to Study", was used in this study. Students were asked to respond to the 52 items in the questionnaire and rate themselves on a Likert scale of 1 to 5 (1-low, 5-high). Sub-scale scores were then calculated by adding together the responses on the items in that sub-scale. Scores on the three main approaches were created by adding together the sub-scale scores which contribute to each learning approach.

\section{Statistical analysis}

Data were analyzed using SPSS software, version 16.0. The demographic variables of the study sample were described using descriptive statistics. Brown-Forsythe test was used to analyze the relationship 
between the learning approach and the educational level.

\section{Results}

Table 1 illustrates the demographic details of the participants. From a total of 138 participants, 46 (33.3\%) were males and 92 (66.7\%) were females. There were 107 (77.5\%) pre-clinical medical undergraduates and 31 (22.5\%) pre-interns.

Among the 138 participants, the predominant learning approach was SA used by 108 students $(78.3 \%)$ while $21(15.2 \%)$ used (DA) and SAA was used by 9 students (6.5\%). A majority of both pre-clinical undergraduates $(77.6 \%)$ and pre-interns $(80.6 \%)$ followed SA. SA was also the predominant learning approach used by both males (69.6\%) and females (82.6\%). Table 2 shows the distribution of the learning approaches according to gender and educational level. Mean scores for the three approaches were not significantly different between the pre-clinical and pre-intern groups (Table 3).

Table 1

Demographics of participants

\begin{tabular}{|llcc|}
\hline Variable & & N & $\%$ \\
\hline Gender & Male & 46 & 33.3 \\
\hline Educational level & Female & 92 & 66.7 \\
\hline & Pre-clinical & 107 & 77.5 \\
\hline & Pre-intern & 31 & 22.5 \\
\hline
\end{tabular}

Table 2

Distribution of the learning approaches according to gender and educational level

\begin{tabular}{|c|c|c|c|c|c|c|c|c|}
\hline & \multicolumn{4}{|c|}{ Gender } & \multicolumn{4}{|c|}{ Educational level } \\
\hline & \multicolumn{2}{|c|}{ Male } & \multicolumn{2}{|c|}{ Female } & \multicolumn{2}{|c|}{ Pre-clinical } & \multicolumn{2}{|c|}{ Pre-intern } \\
\hline & $\mathbf{N}$ & $\%$ & $\mathbf{n}$ & $\%$ & $\mathbf{N}$ & $\%$ & $\mathbf{N}$ & $\%$ \\
\hline Deep Approach (DA) & 10 & 21.7 & 11 & 12.0 & 18 & 16.8 & 3 & 9.7 \\
\hline Strategic Approach (SA) & 32 & 69.6 & 76 & 82.6 & 83 & 77.6 & 25 & 80.6 \\
\hline Surface Apathetic Approach (SAA) & 4 & 8.7 & 5 & 5.4 & 6 & 5.6 & 3 & 9.7 \\
\hline
\end{tabular}


Table 3

Comparison of the learning approaches between the preclinical and pre-intern groups

\begin{tabular}{|llllll|}
\hline & Educational level & N & Mean & SD & Sig \\
\hline Deep Approach (DA) & Preclinical & 107 & 60.38 & 11.924 & 0.186 \\
& Pre-interns & 31 & 57.32 & 10.962 & \\
\hline Strategic Approach (SA) & Preclinical & 107 & 71.52 & 14.610 & 0.220 \\
\hline Surface Apathetic Approach (SAA) & Pre-interns & 31 & 67.90 & 14.197 & \\
& Preclinical & 107 & 50.64 & 10.674 & 0.787 \\
\hline & Pre-interns & 31 & 50.10 & 9.672 & \\
\hline
\end{tabular}

\section{Discussion}

In our study, we discovered that a vast majority of students utilized SA as their preferred learning approach. This was the same between both genders as well as between preclinical students and preintern doctors. This is in keeping with the study done by Samarakoon et al. (2) which analyzed the learning approaches of 147 participants comprising of medical students from the first year and the final year of the University of Colombo as well as students from the Postgraduate Institute of Medicine, Colombo. A study done in Singapore (11) yielded similar results in a cohort of 238 medical students with $50.8 \%$ using SA.

The predominance of the use of SA to learning as opposed to DA reveals important facts about the current medical curriculum as well as the students' learning preference. In studies done by Biggs and Entwistle $(7,8)$, they discovered that strategic learners were motivated by achievement and a sense of competition. They were also academically more successful, achieved higher grades than those who used other approaches and were found to have the lowest level of anxiety (12). Since only the very high performers at the GCE Advanced Level examination are selected to gain entry into the Sri Lankan state medical faculties, it is likely that at the secondary school level also these students have used the SA; the same pattern seems to persist during their undergraduate period as well. The competition prevalent within medical schools coupled with the heavy workload and tight schedules may promote this approach among students keen to survive and flourish in a fast-paced environment.

However, in a study performed in Saudi Arabia (13), DA was found to be the predominant approach among 610 first, second and third year medical students. Cebeci et al. (14) conducted a study among 287 medical students in Ankara, Turkey at the beginning of first, second and third years, determined that the medical students mostly preferred DA. This may be due to the fact that students in their preclinical years have comparatively more time to engage in deep learning as opposed to those in their clinical years where the speed of learning is just as important as the depth of knowledge in the subject matter. Another reason may be that students may have developed their approaches before university entry. In the Sri 
Lankan setting, academic achievements are held in great esteem and students are trained to perform well in pre-university examinations by both school teachers and private tutors. When gaining higher scores and performing well is deemed more important than in-depth understanding of the content, it is a realistic assumption that students would prefer the technique that helps them succeed in their studies.

In our study, the mean scores of the three approaches remained consistent between the preclinical and pre-intern groups and we did not find a significant difference among the usage of the three learning approaches between the two groups. The study by Chonkar et al. (11) revealed that demographic characteristics such as age, gender and highest educational achievement had no influence over the predominant learning approach. This appears to imply that learning approaches were somewhat fixed and students continue to use their preferred approach even as they progress along the academic ladder.

In contrast, in a previous study done in Sri Lanka (2), postgraduates had a significantly higher mean scores for both DA and SA than first years or final years $(p<0.05)$. Mean scores for the SAA did not differ significantly between groups. This study revealed a shift towards DA and SA in postgraduate students. Postgraduate students are involved in more hands-on training and less instructor-centered teaching and they spend less time engaged in traditional studying compared to undergraduate medical students. As patient management based learning is used widely at this level of education and this method promotes active learning and thereby, DA (15). These factors may explain the reason for the rise of the preference for DA to attain a more complete understanding of the subject (16).

The importance of identifying the learning approach of students is not just limited to maximizing their educational achievement although it has been identified that DA and SA are associated with better grades at medical school (17). Knowledge about the learning approaches used by students in the faculty is also helpful when developing and modifying the curriculum in order to provide the best possible education to the students. The approach to learning is a combination of the preferred learning styles as well as the context (4). A high workload and assessments that do not promote deep learning inevitably promote SAA, whereas problem-based learning promotes DA (15).

Considering this, educators can help create a learning environment that facilitates deep learning by recognizing the limitations to it in the medical curriculum and moving from a lecture-based theoretical approach to problem-based student-centered interactive approach. Current evidence demonstrates that students' learning approaches can change and more adaptive approaches may be learnt. Helping students develop their own positive learning approach is more effective than attempting to alter their learning styles (17).

\section{Limitations}

Our study was limited by the small sample size and involved third year students and those who had recently faced their final examinations. More participants from different years of the medical school including the first year students should be included in the study to get clear understanding of the trends in the use of learning approaches over the years. Furthermore, postgraduate students could be included to 
analyze whether specialist education had an impact on the learning approach. In addition, a longitudinal study could be performed to observe whether any change in the predominant learning approach occurs in medical students over the span of their time in the medical school.

\section{Conclusions}

The strategic learning approach is preferred by a majority of pre-clinical students and pre-intern doctors. This brings to attention the fact that the use of this approach has remained persistently over the undergraduate period. Therefore, educators need to consider this when they make adjustments to the medical curricula in order to promote a more holistic deep learning approach.

\section{Abbreviations}

DA

Deep approach

SA

Strategic approach

SAA

Surface apathetic approach

\section{Declarations}

\section{Ethics approval and consent to participate}

Ethical approval for the study was obtained from the Ethics Review Committee of the Faculty of Medical Sciences, University of Sri Jayewardenepura (Application Number: 45/17). Informed consent was obtained from all participants.

\section{Consent for publication}

Not applicable

\section{Availability of data and materials}

The datasets used and/or analysed during the current study are available from the corresponding author on reasonable request.

\section{Competing interests}

The authors declare that they have no competing interests.

\section{Funding}

No funding was received for conducting this study. 


\section{Authors' contributions}

SE, DDS, HD and SY contributed to conceptualization and designing of the study, data analysis and interpretation and writing and revising of the manuscript. IL, MN, KM, SD and CW were involved in data acquisition. All authors read and approved the final manuscript.

\section{Acknowledgements}

Not applicable

\section{References}

1. Koh GCH, Khoo HE, Wong ML, Koh D. The effects of problem-based learning during medical school on physician competency: A systematic review. CMAJ [Internet]. 2008 Jan 1 [cited 2021 May 9];178(1):34-41. Available from: /pmc/articles/PMC2151117/

2. Samarakoon L, Fernando T, Rodrigo C, Rajapakse S. Learning styles and approaches to learning among medical undergraduates and postgraduates. BMC Med Educ [Internet]. 2013 Dec 25;13(1):42. Available from: https://bmcmededuc.biomedcentral.com/articles/10.1186/1472-6920-13-42

3. Lubawy WC. Evaluating teaching using the best practices model [Internet]. Vol. 67, American Journal of Pharmaceutical Education. American Association of Colleges of Pharmacy; 2003 [cited 2021 May 9]. p. 87. Available from: https://experts.unthsc.edu/en/publications/evaluating-teaching-using-thebest-practices-model

4. Newble DI, Entwistle NJ. Learning styles and approaches: implications for medical education. Med Educ. 1986;20(3):162-75.

5. Cuthbert PF. The student learning process: Learning Styles or Learning Approaches? [Internet]. Vol. 10, Teaching in Higher Education. Taylor \& Francis Group; 2005 [cited 2021 May 9]. p. 235-49. Available from: https://www.tandfonline.com/doi/abs/10.1080/1356251042000337972

6. Tait H, Entwistle N, McCune V. ASSIST: A reconceptualisation of the approaches to studying inventory. Improving student learning: Improving students as learners. 1998;

7. Biggs J. Individual Differences in Study Processes and the Quality of Learning Outcomes. High Educ. 1979 Jul;8(4):381-94.

8. Entwistle NJ., Ramsden P. Understanding Student Learning [Internet]. 1983 [cited 2021 May 9]. Available from: https://eric.ed.gov/?id=ED244959

9. Leite WL, Svinicki M, Shi Y. Attempted validation of the scores of the VARK: Learning styles inventory with multitrait-multimethod confirmatory factor analysis models. Educ Psychol Meas [Internet]. 2010 Aug 31 [cited 2021 May 9];70(2):323-39. Available from: https://journals.sagepub.com/doi/abs/10.1177/0013164409344507

10. Kleijn WC, van der Ploeg HM, Topman RM. Cognition, study habits, test anxiety, and academic performance. Psychol Rep [Internet]. 1994 [cited 2021 May 9];75(3 Pt 1):1219-26. Available from: /record/1995-27739-001 
11. Chonkar SP, Ha TC, Chu SSH, Ng AX, Lim MLS, Ee TX, et al. The predominant learning approaches of medical students. BMC Med Educ. 2018;18(1):1-8.

12. Cipra C, Müller-Hilke B. Testing anxiety in undergraduate medical students and its correlation with different learning approaches. PLoS One. 2019 Mar 13;14(3).

13. Shaik SA, Almarzuqi A, Almogheer R, Alharbi O, Jalal A, Alorainy M. Assessing Saudi medical students learning approach using the revised two-factor study process questionnaire. Int $\mathrm{J}$ Med Educ. 2017;8:292-6.

14. Cebeci S, Dane S, Kaya M, Yigitoglu R. Medical Students' Approaches to Learning and Study Skills. Procedia - Soc Behav Sci. 2013;93(October 2013):732-6.

15. Dolmans DHJM, Loyens SMM, Marcq H, Gijbels D. Deep and surface learning in problem-based learning: a review of the literature. Adv Heal Sci Educ. 2016 Dec 13;21(5).

16. Marton F, Säaljö R. On qualitative differences in learning-ii outcome as a function of the learner's conception of the task. Br J Educ Psychol [Internet]. 1976 Jun 1 [cited 2021 May 9];46(2):115-27. Available from: https://bpspsychub.onlinelibrary.wiley.com/doi/full/10.1111/j.20448279.1976.tb02304.x

17. Feeley A-M, Biggerstaff DL. Exam Success at Undergraduate and Graduate-Entry Medical Schools: Is Learning Style or Learning Approach More Important? A Critical Review Exploring Links Between Academic Success, Learning Styles, and Learning Approaches Among School-Leaver Entry ("Traditional") and Graduate-Entry ("Nontraditional”) Medical Students. Teach Learn Med. 2015 Jul $3 ; 27(3)$. 